Check for updates

Cite this: Phys. Chem. Chem. Phys., $2018,20,20043$

Received 8th March 2018, Accepted 11th July 2018 DOI: $10.1039 / c 8 c p 01535$ rsc.li/pccp

\section{Short-range ion dynamics in methylammonium lead iodide by multinuclear solid state NMR and ${ }^{127}$ I NQR†}

\author{
Alessandro Senocrate, (D) Igor Moudrakovski (D) * and Joachim Maier (D)
}

\section{Introduction}

The outstanding photo-electrochemical properties of hybrid organic-inorganic halide perovskites have motivated in recent years a massive number of studies on these promising solar cell materials. ${ }^{1-3}$ Even though these compounds were described nearly 40 years ago, ${ }^{4}$ the characterization of their properties and application in devices is much more recent. ${ }^{1,5}$ Despite the momentous effort already spent in characterizing these materials, a significant portion of the physics and chemistry underlying their properties is still missing. As a notable example, the short-range dynamics of the organic cations is still not well understood, despite being of great importance since it is linked to the long carrier lifetimes in these systems. ${ }^{6-8}$ In addition, the interaction of the organic cations with the inorganic framework through hydrogen bonding ${ }^{9}$ has been suggested to contribute to the stabilization of the structure ${ }^{10}$ while also influencing the optical and electronic properties of the materials. ${ }^{11,12}$ Therefore, the goal of the present study is to probe such short-range ion dynamics in the archetypal halide perovskite $\mathrm{MAPbI}_{3}$ via solid-state NMR $\left({ }^{1} \mathrm{H},{ }^{13} \mathrm{C},{ }^{14} \mathrm{~N},{ }^{15} \mathrm{~N}\right.$ and $\left.{ }^{207} \mathrm{~Pb}\right)$ and Nuclear Quadrupolar Resonance $\left({ }^{127} \mathrm{I} \mathrm{NQR}\right)$, with particular attention to the rotational motion of the methylammonium (MA) cation, as well as to the interaction

Department of Physical Chemistry of Solids, Max Planck Institute for Solid State Research, Heisenbergstr. 1, 70569, Stuttgart, Germany.

E-mail: i.moudrakovski@fkf.mpg.de

$\dagger$ Electronic supplementary information (ESI) available. See DOI: 10.1039/c8cp01535j between MA and the inorganic lattice. Long-range ion dynamics, that gives rise to a significant iodine conductivity in $\mathrm{MAPbI}_{3}$, was studied by our group in a previous work. ${ }^{13}$

Owing to its unsurpassed sensitivity to short-range interactions, NMR spectroscopy is very effective to study dynamic processes, ${ }^{14-18}$ and its first applications to the investigation of halide perovskites go back as early as $1985 .{ }^{19-22}$ In these studies, reorientation of the organic moiety was observed in all crystalline phases of $\mathrm{MAPbI}_{3}$ (but also $\mathrm{MAPbBr}_{3}$ and $\mathrm{MAPbCl}_{3}$ ) through ${ }^{1} \mathrm{H},{ }^{2} \mathrm{H}$ and ${ }^{14} \mathrm{~N}$ spinlattice relaxation times $\left(T_{1}\right)$ measurements. ${ }^{20-22}$ Even though decreasing the temperature naturally hinders MA reorientation, rotation about the $\mathrm{C}-\mathrm{N}$ axis in a correlated fashion was observed down to $50 \mathrm{~K}$. The phase transitions (orthorhombic-tetragonal at $162 \mathrm{~K}$ and tetragonal-cubic at $327 \mathrm{~K})^{23}$ are not visible in the $T_{1}$ measurements of ${ }^{2} \mathrm{H}$ and ${ }^{14} \mathrm{~N},{ }^{21}$ but can be detected by ${ }^{1} \mathrm{H}$ measurements, ${ }^{22}$ albeit only the lower temperature transition was investigated. More recently, NMR spectroscopy has been applied to halide perovskites to investigate the effects of degradation, ${ }^{24}$ extended defects and crystal quality ${ }^{25}$ and details of $\mathrm{Pb}-\mathrm{X}$ environment and cation dynamics. ${ }^{13,26-29}$

In this work, we report on NMR and NQR spectra discussed in light of molecular dynamics simulations and relaxation effects. First we look at the MA cation with ${ }^{1} \mathrm{H},{ }^{13} \mathrm{C},{ }^{14} \mathrm{~N}$ and ${ }^{15} \mathrm{~N}$ NMR as a function of temperature and corresponding relaxation time measurements. Combination of these data will show that the motion of the MA cation in $\mathrm{MAPbI}_{3}$ can be well described by a bi-axial rotation, with similar interactions of $\mathrm{CH}_{3}$ and $\mathrm{NH}_{3}{ }^{+}$groups with the inorganic framework. This motion 
develops into a nearly isotropic rotation above the cubic phase transition, becoming a dominant contribution to the spinlattice relaxation of ${ }^{1} \mathrm{H},{ }^{13} \mathrm{C}$ and ${ }^{15} \mathrm{~N}$ through spin-rotational interactions. We follow by presenting ${ }^{207} \mathrm{~Pb}$ NMR and ${ }^{127} \mathrm{I}$ NQR spectroscopic and relaxation data, where we observe strong cross-relaxation between ${ }^{207} \mathrm{~Pb}$ and ${ }^{127} \mathrm{I}$, which fully dominates spin-spin and spin-lattice relaxation in ${ }^{207} \mathrm{~Pb}$.

\section{Experimental part}

\section{Synthesis}

As a first step, MAI was prepared according to a modified reported procedure. ${ }^{30}$ Single crystals of $\mathrm{MAPbI}_{3}$ were then obtained as reported by Saidaminov, ${ }^{31}$ using an equimolar mixture of MAI and commercial $\mathrm{PbI}_{2}$ powders (99.9995\%, Alfa Aesar). The synthesis step was carried out in normal laboratory atmosphere. These single crystals were subsequently crushed under inert atmosphere to obtain crystalline powders and directly transferred into the appropriate NMR sample holders, which were sealed to prevent exposure to oxygen and humidity. In order to synthetize ${ }^{13} \mathrm{C}$ - and ${ }^{15} \mathrm{~N}$-labelled $\mathrm{MAPbI}_{3}$, we used commercial ${ }^{13} \mathrm{C},{ }^{15} \mathrm{~N}$ methylamine (99\% enrichment, SigmaAldrich) to obtain labelled MAI, that was used in the single crystal synthesis step to yield labelled $\mathrm{MAPbI}_{3}$ containing $20 \%$ ${ }^{13} \mathrm{C}$ and ${ }^{15} \mathrm{~N}$. Powder XRD data on the crushed single crystals are given in the (Fig. S1, ESI $\dagger$ ).

\section{NMR measurements}

The majority of NMR measurements were performed on a Bruker Avance III $400 \mathrm{MHz}$ instrument at magnetic field of 9.4 T. Measurements with stationary samples used a Bruker PE400 double resonance high power probe with a $5 \mathrm{~mm}$ solenoid coil. The spectra of ${ }^{14} \mathrm{~N}$ and ${ }^{207} \mathrm{~Pb}$ were obtained using solid-echo $(\pi / 2-\tau-\pi / 2)$ and Hahn-echo $(\pi / 2-\tau-\pi)$ pulse sequences with $\tau=20 \mu \mathrm{s}$, and the relaxation delays set to provide for a complete relaxation (1s for ${ }^{14} \mathrm{~N}$ and $5 \mathrm{~s}$ for ${ }^{207} \mathrm{~Pb}$ at room temperature). Between 100 and 400 scans were accumulated for both nuclei. ${ }^{1} \mathrm{H}$ spectra were acquired with simple Bloch Decay experiment (i.e., pulse-acquisition), with the $\pi / 2$ pulse of $2.5 \mu \mathrm{s}$, and the relaxation delay set long enough for a complete relaxation $(10 \mathrm{~s}$ at room temperature). ${ }^{13} \mathrm{C}$ and ${ }^{15} \mathrm{~N}$ spectra were obtained using Bloch decay experiment accompanied by a composite proton decoupling. The excitation $\pi / 2$ pulses were $5 \mathrm{~ms}$ and $6 \mathrm{~ms}$, and relaxation delays at room temperature of $150 \mathrm{~s}$ and $600 \mathrm{~s}$, respectively. For isotopically enriched samples between 16 and 64 scans were commonly accumulated. Unless stated otherwise, spin-lattice relaxation time measurements were performed in stationary conditions, mainly with the saturation-recovery technique $^{32}$ in order to minimize the experimental time.

The experiments with Magic Angle Spinning (MAS) used a Bruker BL4 double resonance MAS probe with $4 \mathrm{~mm}$ OD $\mathrm{ZrO}_{2}$ spinners. Dry nitrogen was used as spinning, bearing, and cooling gas. The spinning rate was, when possible, kept between 10 and $14 \mathrm{kHz}$. The spectra were acquired using ramped Cross Polarization (CP) and also Bloch Decay, both accompanied by composite proton decoupling at the proton RF power of $50 \mathrm{kHz}$. The temperature in the probes was regulated with a Bruker BVT3000 temperature controller. Actual temperature inside the spinner was calibrated on ${ }^{207} \mathrm{~Pb}$ signal of powdered $\mathrm{Pb}\left(\mathrm{NO}_{3}\right)_{2} \cdot{ }^{33}$ Chemical shifts were referenced externally relative to TMS $\left({ }^{1} \mathrm{H}\right.$ and $\left.{ }^{13} \mathrm{C}, \delta_{\text {iso }}=0.0 \mathrm{ppm}\right)$, tetramethyl lead $\left({ }^{207} \mathrm{~Pb}, \delta_{\text {iso }}=\right.$ $0.0 \mathrm{ppm}$, set with the absolute referencing to TMS), nitromethane $\left({ }^{14,15} \mathrm{~N}, \delta_{\text {iso }}=0.0 \mathrm{ppm}\right.$, set with the secondary reference of $\mathrm{NH}_{4} \mathrm{Cl}$, $\left.\delta_{\text {iso }}=-341.2 .0 \mathrm{ppm}\right) .^{34}$

NQR measurements were performed using the same spectrometer console and probes, which were kept at a sufficient distance from the magnet to avoid the effects of stray magnetic fields. All RF-pulses have been calibrated directly on a sample of $\mathrm{MAPbI}_{3}$, with $\pi / 2$ pulses being adjusted to $2 \mu$ s. A solid-echo $\pi / 2-\tau-\pi / 2$ pulse sequence with $\tau=20 \mu$ s and relaxation delay of $2 \mathrm{~ms}$ has been used to acquire the spectra, with the number of accumulations being between 128 and 256. Pure NQR spin-lattice relaxation times have been measured using inversionrecovery method.

\section{DFT calculations}

All calculations were performed with the Castep code $^{35,36}$ integrated within the Biovia Materials Studio 2017 suite. The computations use the generalized gradient approximation (GCA) and Perdew-Burke-Ernzerhof (PBE) functional, ${ }^{37}$ with the core-valence interactions described by ultra-soft pseudopotentials. $^{28}$ A Monkhorst-Pack grid ${ }^{38}$ was used to realize integrations over the Brillouin zone, with $k$ point spacings generally being less than $0.04 \AA^{-1}$. The convergence of the calculated NMR parameters was tested for both the size of a Monkhorst-Pack k-grid and a basis set cut-off energy, with cut-off energies being in the range of 550-610 eV. To account for relativistic effects in such heavy elements as lead and iodine, all calculations were performed including the zerothorder regular approximation (ZORA) ${ }^{39,40}$ through scalar-relativistic pseudopotentials. ${ }^{41}$ Geometry optimization calculations were performed using the Broyden-Fletcher-Goldfarb-Shanno (BFGS) algorithm, with the same functional, k-grid spacings and cut-off energies as in the single-point energy calculations. Convergence tolerance parameters for geometry optimization were as follows: maximum energy $2 \times 10^{-5} \mathrm{eV}$ per atom, maximum force $0.05 \mathrm{eV} \AA^{-1}$, maximum stress $0.1 \mathrm{GPa}$ and maximum displacement $0.002 \AA$. Crystallographic data used in the calculations were taken from the literature. ${ }^{5}{ }^{14} \mathrm{~N}$ NMR parameters in methylammonium cation were calculated in a $3 \times 3 \times 3$ supercell of $\mathrm{MAPbI}_{3}$ after a molecular dynamic simulation run for 1 ps $270 \mathrm{~K}$. During the DFT MD simulation only the cations move, while the lattice parameters of the inorganic framework composed by heavy atoms of iodine and lead are fixed. Fig. S8 (ESI $\dagger$ ) shows the structure before and after the simulations.

\section{Spectral simulations and fitting}

Analytical simulations of the experimental spectra were carried out with the DMFit ${ }^{42}$ simulation package and the SOLAGuide module in TopSpin 3.2 processing software from Bruker. 
${ }^{14} \mathrm{~N}$ NMR line shapes affected by the motion of the MA-cation were simulated with NMR-WEBLAB ${ }^{43}$ and EXPRESS ${ }^{44}$ computational packages.

\section{Results and discussion}

\section{${ }^{1} \mathrm{H}$ solid state NMR}

The isotope ${ }^{1} \mathrm{H}$ offers the highest sensitivity among all NMR active nuclei in $\mathrm{MAPbI}_{3}$. As shown in Fig. 1a, ${ }^{1} \mathrm{H}$ spectra obtained with 10-15 kHz Magic Angle Spinning (MAS) show two well-resolved signals at $3.4 \mathrm{ppm}\left(\mathrm{CH}_{3}\right)$ and $6.4 \mathrm{ppm}\left(\mathrm{NH}_{3}{ }^{+}\right)$, the position of which remain nearly constant between 183 and $373 \mathrm{~K}$ (Fig. S2, ESI $\dagger$ ). On few other occasions, we have observed some minor signals near $0.9 \mathrm{ppm}$ likely due to residual solvent from the synthesis (DMF), while no peaks assignable to water have ever been detected. Although the MAS offers a considerable improvement in spectral resolution, the majority of our measurements have been performed in stationary conditions, since having a consistent spinning of the glass-sealed samples (required to avoid oxygen- and moisture-induced degradation) in the broad range of studied temperatures was rather difficult. A further argument against the MAS measurements was the influence of the spinning on the spin-lattice relaxation time measurements (Fig. S5a, ESI $\dagger$ ), which is also found in other materials. ${ }^{4,46}$ In contrast to spinning samples, the ${ }^{1} \mathrm{H}$ stationary spectra show a broadened, unresolved signal with a $\sim 8 \mathrm{kHz}$ FWHM and a line shape well represented by a Gaussian (Fig. 1a).

Before looking further at the experimental results, it can be helpful to discuss the factors affecting the shape and width of NMR signals. The broadening of ${ }^{1} \mathrm{H}$ NMR signals in a stationary $\mathrm{MAPbI}_{3}$ sample is primarily due to the homonuclear dipoledipole (DD) interaction between protons in the MA cation. Additional contributions come from the heteronuclear interaction between protons and ${ }^{14} \mathrm{~N}$ of the amine group and, to a lesser extent, between protons and the atoms of the inorganic lattice. DD interactions in solids can be quantified by the so-called second moment $M_{2}$ of the spectrum, which can be calculated for ${ }^{1} \mathrm{H}$ in MA based on the geometry of the system (Section 3, ESI $\dagger$ ). We note a substantial deviation of more than 1 order of magnitude between the $M_{2}$ values calculated in a static environment and the experimental values, indicating that the MA cation, along with rotation around the $\mathrm{C}-\mathrm{N}$ axis, must be involved in another reorientation with a symmetry axis higher than 2-fold (for the detailed discussion, see Section 3, ESI $\dagger$ ). Since the methyl and amino groups composing MA have similar masses, such a reorientation is likely a rotational oscillation about an axis passing near the center of the $\mathrm{C}-\mathrm{N}$
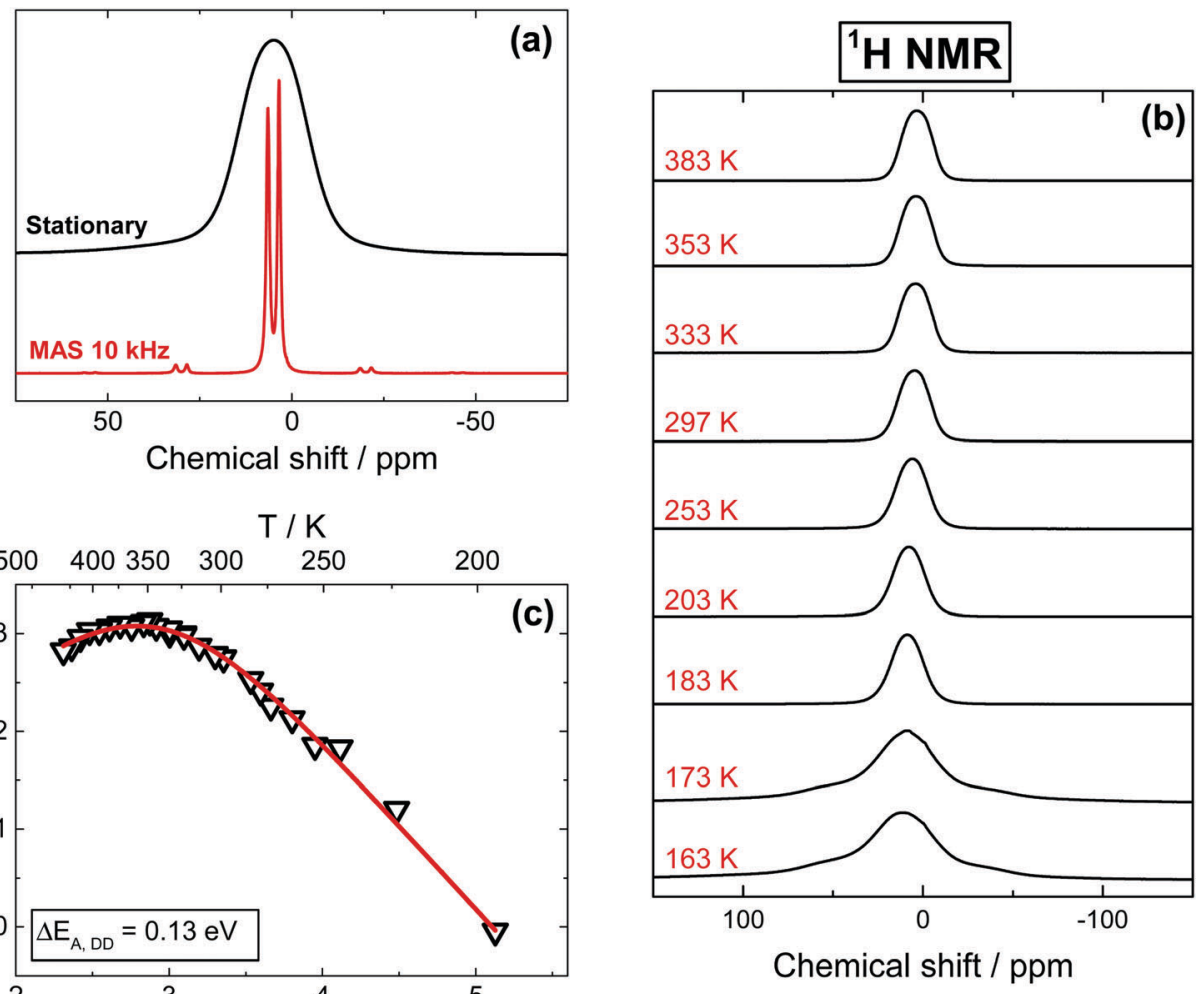

Fig. 1 (a) Stationary and MAS ${ }^{1} \mathrm{H}$ NMR spectra of MAPbl 3 recorded at $297 \mathrm{~K}$. (b) Stationary ${ }^{1} \mathrm{H}$ spectra as a function of temperature. (c) ${ }^{1} \mathrm{H} T_{1}$ relaxation times obtained from stationary spectra. Extracted activation energy values for the dipole-dipole relaxation mechanism dominating at low temperatures is $\Delta E_{\mathrm{A}, \mathrm{DD}}=0.13 \mathrm{eV}$. A value for the spin-rotational contribution of $\Delta E_{\mathrm{A}, \mathrm{SR}}=-0.1 \mathrm{eV}$ is obtained after fitting the entire curve using fixed values initially extracted from the low temperature part. Due to a possibility of sample degradation, only a limited temperature range is available, making the spin-rotational behavior in $T_{1}$ challenging to accurately fit and the resulting activation energy intrinsically only indicative. 
bond, tilted relative to the bond at angle $\theta$ (schematics below in Fig. 5). This composite rotation will give a reduction of $M_{2}$ by a factor $\rho=1 / 16 \cdot\left(3 \cos ^{2} \theta-1\right)^{2} \cdot \cdot^{20,47}$ Since $180^{\circ}$ flips $\left(\theta=180^{\circ}\right)$ are not the dominant motion reducing $M_{2}$ we speculate that a precessional motion of the $\mathrm{C}-\mathrm{N}$ bond tilted at $\theta \leq 60^{\circ}$ is responsible for the small observed $M_{2}$ value, a hypothesis that is in very good agreement with the ${ }^{14} \mathrm{~N}$ NMR results discussed below. The absence of $180^{\circ}$ flips was observed by neutron scattering experiments ${ }^{48}$ and it is also indicated by the quadrupolar splitting visible in our ${ }^{14} \mathrm{~N}$ NMR spectra (given below in Fig. 4a). Note that DD interactions are not completely averaged neither between the protons within the cation, nor to other atoms $\left({ }^{127} \mathrm{I},{ }^{207} \mathrm{~Pb}\right)$ or to protons from neighboring cells. As a result, both line shape and FWHM of ${ }^{1} \mathrm{H}$ stationary signals change very little from $503 \mathrm{~K}$ down to $183 \mathrm{~K}$ (Fig. 1b). Both the temperature independence of ${ }^{1} \mathrm{H}$ FWHM and the small magnitude of $M_{2}$ were previously reported in the tetragonal phases of $\mathrm{MAPbCl}_{3}$ and $\mathrm{MAPbBr}_{3},{ }^{20}$ along with a sharp increase of the second moment after transition into the orthorhombic phase that was assigned to a diminished $C_{3}$ reorientation in the MA cation (i.e., around the $\mathrm{C}-\mathrm{N}$ axis). Similarly, we observe that at $T \leq 173 \mathrm{~K}$ the signal undergoes a drastic transformation, morphing into a broad, poorly resolved triplet with separation between the components of $\sim 18 \mathrm{kHz}$ (Fig. 1b). Such a line shape is expected for a system of three protons at the corners of an equilateral triangle, ${ }^{49,50}$ with separation between the peaks being a function of both distance and mobility of the protons.

Additional information about the overall dynamics and specific modes of motion of MA can be obtained from the ${ }^{1} \mathrm{H}$ spin-lattice relaxation time $\left(T_{1}\right)$ measurements as a function of temperature given in Fig. 1c. Between $183 \mathrm{~K}$ and $310 \mathrm{~K}$, the relaxation is characteristic of the fast motion limit of the Bloembergen-Purcell-Pound (BPP) model, ${ }^{51}$ and is being governed by DD interactions with other protons (Section 4, ESI $\dagger$ ). Assuming an Arrhenius dependence of the motional correlation time $\left(\ln \left(\tau_{\rho}\right) \propto 1 / T_{1}\right)$, we found an activation barrier $\left(\Delta E_{\mathrm{A}, \mathrm{DD}}\right)$ of $0.13 \mathrm{eV}$ for this temperature range, well within the expected range for rotational motion of the MA cation inside the $\mathrm{Pb}-\mathrm{I}$ framework and in good agreement with earlier reports. $^{22}$ We note that the here reported $T_{1}$ values are an average of the proton relaxations in $\mathrm{CH}_{3}$ and $\mathrm{NH}_{3}{ }^{+}$groups, with the respective contributions likely being equal, or at least very similar, since the observed $T_{1}$ is mono-exponential in the whole temperature range, with only a slight deviation near the orthorhombic phase transition (Fig. S3, ESI $\dagger$ ). This monoexponential dependence clearly suggests that $\mathrm{CH}_{3}$ and $\mathrm{NH}_{3}{ }^{+}$ groups interact similarly with the inorganic framework. In contrast, in a previous report, ${ }^{26}{ }^{1} \mathrm{H} T_{1}$ relaxation times measured under MAS conditions were used to claim a preferential interaction of $\mathrm{NH}_{3}{ }^{+}$groups with the inorganic framework, albeit the difference in $T_{1}$ between the two groups was rather small and likely within experimental error. We have also measured ${ }^{1} \mathrm{H} T_{1}$ relaxation times under MAS conditions (Fig. S5a, ESI $\dagger$ ), and observed similarly minor differences between the relaxation times of the two groups. We believe that this very minor discrepancy, in conjunction with the strong influence of
MAS conditions on $T_{1}$ relaxation times, ${ }^{45,46}$ makes the above claims of preferential interactions unwarranted.

As expected, the relaxation times observed for ${ }^{1} \mathrm{H}$ in pure $\mathrm{MAPbI}_{3}$ and in ${ }^{13} \mathrm{C},{ }^{15} \mathrm{~N}$-labelled samples are identical within experimental error; a similar activation energy is also found for $\mathrm{MAPbBr}_{3}$ (Fig. S4, ESI $\dagger$ ). Interestingly, as seen in Fig. 1c, above room temperature $T_{1}$ makes a downward turn, that is characteristic of spin-rotational (SR) interaction. As we will show below, the same behavior is present for ${ }^{13} \mathrm{C}$ and ${ }^{15} \mathrm{~N}$ in $\mathrm{MAPbI}_{3}$, and was reported for ${ }^{1} \mathrm{H}$ in $\mathrm{MAPbBr}_{3}$ (also Fig. S4, ESI $\dagger$ ) and $\mathrm{MAPbCl}_{3} \cdot{ }^{20}$ The relaxation rate is therefore defined by a combination of two processes, namely by a dipole-dipole and a spin-rotational mechanism, the latter becoming dominant in the vicinity of the tetragonal to cubic phase transition where the increased free space in the inorganic cage allows for a less hindered (and thus faster) MA rotation. As expected, in the case of ${ }^{1} \mathrm{H} T_{1}$ measurements in $\mathrm{MAPbBr}_{3}$ (Fig. S4, ESI $\dagger$ ), the inversion behavior takes place at lower temperatures, albeit notably not as low as the phase transition into the cubic phase $(237 \mathrm{~K}) .^{23}$ This observation is consistent with previous reports. ${ }^{20}$ Lastly, we note that while we can accurately extract an activation energy for DD relaxation (given above), the experimentally accessible temperature range in which SR contributions dominate is rather narrow, making the estimate of such activation energy inaccurate (see caption of Fig. 1).

\section{${ }^{13}$ C NMR}

The ${ }^{13} \mathrm{C}$ spectra, as shown in Fig. 2a, give a better spectral resolution than ${ }^{1} \mathrm{H}$ NMR, though at the expense of substantially longer acquisition times due to the low natural abundance of the isotope $(1.1 \%)$. To overcome this issue, we use a ${ }^{13} \mathrm{C}$-labelled sample (20\% enrichment). Both Cross-Polarization (CP) from protons and direct excitation (Bloch Decay accumulation) combined with the high power proton decoupling (HPDEC) sequence can be successfully used. While in many organic materials CP usually offers a better sensitivity because of the shorter ${ }^{1} \mathrm{H}$ relaxation times and effective $\mathrm{CP}$ dynamics, this is not the case for $\mathrm{MAPbI}_{3}$. Slow proton magnetization recovery and a very fast relaxation in the rotating frame $T_{1 \rho}$ make CP very ineffective above $250 \mathrm{~K}$ (Fig. S5b, ESI $\dagger$ ). In contrast, the direct excitation is less affected by the MA dynamics and here the relative intensities of the signals reflect quantitatively the concentration of different sites, making this our approach of choice. MAS has also been applied in order to obtain better resolved spectra (Fig. 2a and Fig. S7a, ESI $\dagger$ ). However, since our preliminary results indicated an influence of MAS on ${ }^{13} \mathrm{C} T_{1}$ relaxation times (Section 5, see also Fig. S6, ESI $\dagger$ ), as also reported for other materials, ${ }^{45,46,52}$ all $T_{1}$ measurements were performed in stationary conditions.

${ }^{13} \mathrm{C}$ spin-lattice relaxation times can be composed of contributions from three primary relaxations mechanisms, ${ }^{53-55}$ such as: (i) heteronuclear DD interactions with protons, (ii) relaxation due to the chemical shift anisotropy (CSA) and (iii) relaxation due to SR interactions (as in protons). We leave the full expressions of the relaxation mechanism and of the related contributions to the ESI, $\dagger$ (Section 5); here it suffices to say that the nearly symmetrical signal shape even at very low temperatures 

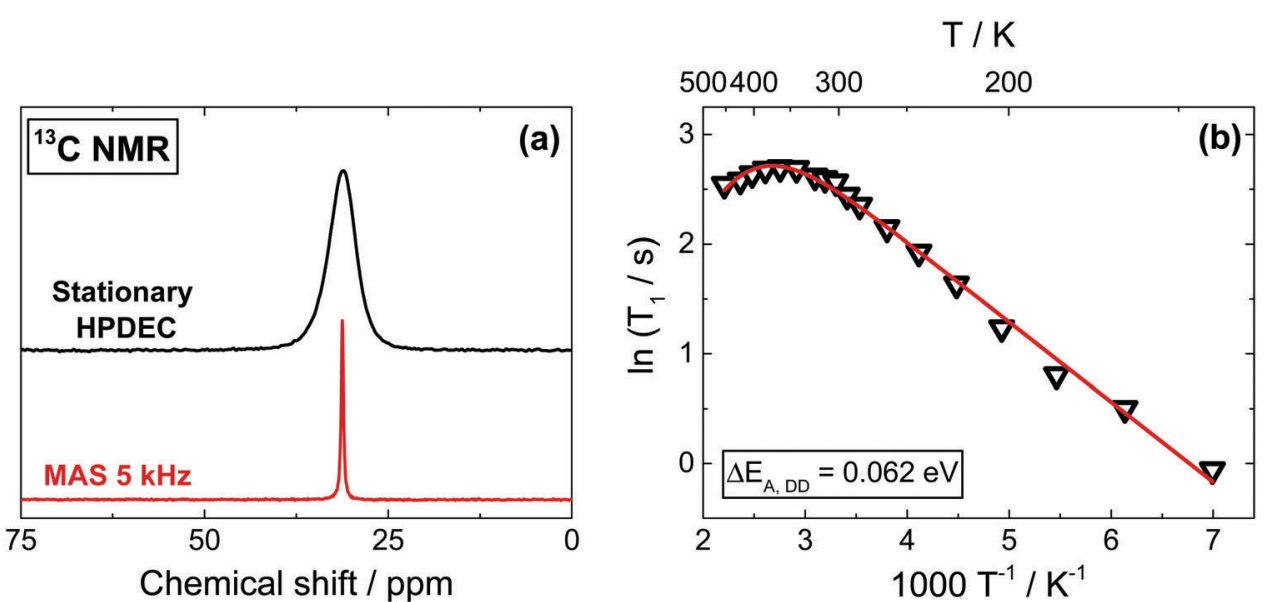

Fig. 2 (a) ${ }^{13} \mathrm{C}$ stationary and MAS NMR spectra in $\left({ }^{13} \mathrm{C},{ }^{15} \mathrm{~N}\right)$-labelled MAPbl 3 . (b) Spin-lattice relaxation time extracted from stationary ${ }^{13} \mathrm{C}$ NMR spectra as a function of temperature. The activation energy $\left(\Delta E_{\mathrm{A}, \mathrm{DD}}=0.062 \mathrm{eV}\right)$ was extracted from the linear low temperature part, and the obtained value was used to generate the complete fit, yielding $\Delta E_{\mathrm{A}, \mathrm{SR}}=-0.38 \mathrm{eV}$. Again, the narrow range accessible at high temperatures makes the activation energy for SR highly inaccurate.

suggest a negligible contribution of CSA in ${ }^{13} \mathrm{C}$ spectra. This is in agreement with $a b$ initio DFT calculations on the tetragonal phase of $\mathrm{MAPbI}_{3}$ yielding a very small value (38 ppm) for the shielding anisotropy (Table S1, ESI†). As shown in Fig. $2 \mathrm{~b},{ }^{13} \mathrm{C} T_{1}$ measurements as a function of temperature present a linear trend in the Arrhenius dependence below $340 \mathrm{~K}$, as expected from DD interactions dominating the relaxation $\left(\Delta E_{\mathrm{A}, \mathrm{DD}}=0.062 \mathrm{eV}\right)$. Analogously to ${ }^{1} \mathrm{H}$ and ${ }^{15} \mathrm{~N}$ (below), above room temperature we observe an inversion of the trend, corresponding to a change in dominant relaxation mechanism from DD to a SR interaction. Again, the trend inverts close to the tetragonal to cubic phase transition, relating it to the increased free space of the inorganic framework giving a reduced obstruction to the rotation of the MA cation.

\section{${ }^{15}$ N NMR}

Due to very low natural abundance $(0.4 \%),{ }^{15} \mathrm{~N}$ spectra are barely detectable in non-labelled $\mathrm{MAPbI}_{3}$. However, since ${ }^{15} \mathrm{~N}$ NMR can produce highly resolved spectra, especially when combined with $\mathrm{CP}$ and proton decoupling, we use a ${ }^{15} \mathrm{~N}$-labelled sample $(20 \%$ enrichment) to record the spectra (Fig. 3a). MAS conditions have also been applied in order to obtain better resolved spectra (Fig. 3a and Fig. S7b, ESI $\dagger$ ). The relaxation mechanisms expecting to contribute into ${ }^{15} \mathrm{~N} T_{1}$ are the same as those discussed for ${ }^{13} \mathrm{C}$ and described in the previous section (and in Section 5, ESI†). Also here, we can reliably rule out any significant contribution of the CSA to the relaxation process based on our ab initio DFT calculations, which give a low value of $10.2 \mathrm{ppm}$ (Table S1, ESI $\dagger$ ) for the ${ }^{15} \mathrm{~N}$ shielding anisotropy, which is by at least two orders of magnitude too small to produce any appreciable contribution to $T_{1}$.

Also here, $T_{1}$ demonstrates a linear trend in the tetragonal phase, as expected for internuclear proton-nitrogen DD relaxation in the fast motion limit $\left(\Delta E_{\mathrm{A}, \mathrm{DD}}=0.084 \mathrm{eV}\right)$, which turns into a negative temperature dependence in the cubic phase due
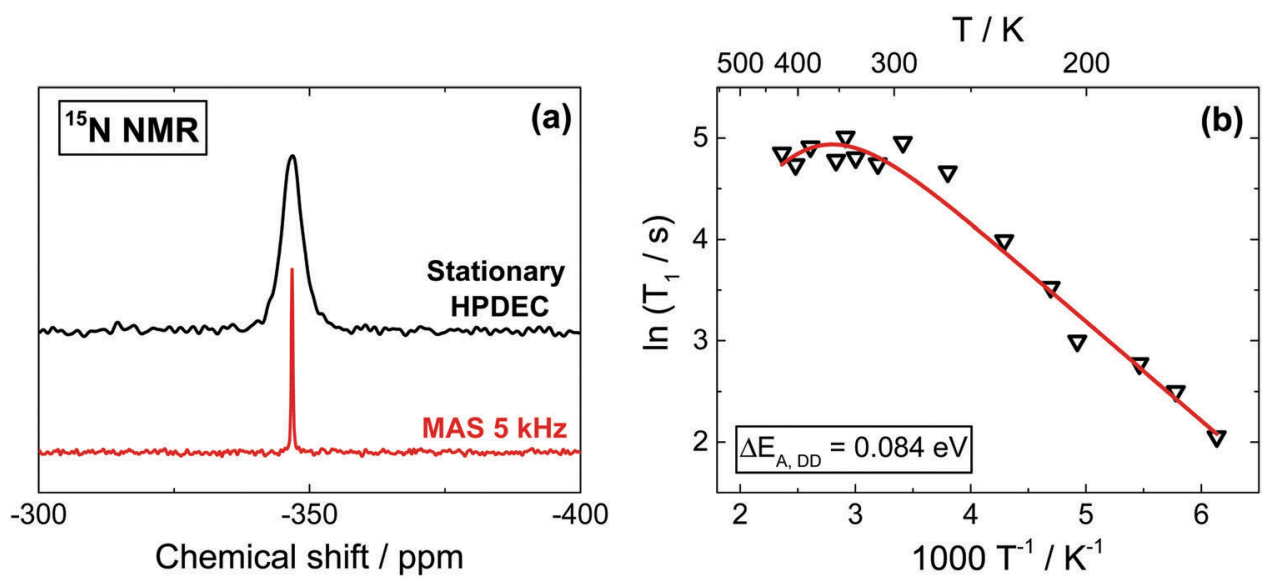

Fig. 3 (a) ${ }^{15} \mathrm{~N}$ stationary and MAS spectra $\left({ }^{13} \mathrm{C},{ }^{15} \mathrm{~N}\right)$-enriched $\mathrm{MAPb}_{3}$. (b) ${ }^{15} \mathrm{~N}$ Spin-lattice relaxation time $T_{1}$ extracted from stationary spectra. The activation energy $\left(\Delta E_{\mathrm{A}, \mathrm{DD}}=0.084 \mathrm{eV}\right)$ was extracted from the linear low temperature part, and the obtained value was subsequently used to generate the complete fit, yielding $\Delta E_{\mathrm{A}, \mathrm{SR}}=-0.17 \mathrm{eV}$. Also here, the narrow range accessible at high temperatures yields a highly inaccurate activation energy value for the SR contribution. 
to the increasingly dominating SR contribution. The rather small difference between the activation barriers of the DD relaxation in ${ }^{13} \mathrm{C}$ and ${ }^{15} \mathrm{~N}$ is expected for an almost symmetrical rotor such as $\mathrm{CH}_{3}-\mathrm{NH}_{3}{ }^{+}$. In addition, the activation energy extracted from ${ }^{1} \mathrm{H} \mathrm{T}_{1}$ measurements is comparable with the ones of ${ }^{13} \mathrm{C}$ and ${ }^{15} \mathrm{~N}$, as expected since they refer to the same motion (and to the same type of relaxation process).

\section{${ }^{14}$ N NMR}

Fig. 4a shows ${ }^{14} \mathrm{~N}$ NMR spectra of $\mathrm{MAPbI}_{3}$ in the tetragonal and cubic phases. ${ }^{13}$ In the tetragonal phase, the spectrum is dominated by quadrupolar interactions, demonstrating a typical spin-1 powder pattern with axial symmetry of the electric field gradient (EFG), while in the cubic phase the quadrupolar interactions are averaged, and therefore the splitting absent. Spin-lattice relaxation time $T_{1}$ becomes longer with the temperature (Fig. 4b), indicating fast motion limit for the dominant relaxation mechanism in the whole studied range $(183 \mathrm{~K}$ to $503 \mathrm{~K}$ ). For a spin-1 nucleus such as ${ }^{14} \mathrm{~N}$, the dominating mechanism of spin-lattice relaxation is due to quadrupolar interactions. In the fast motion limit, such quadrupolar relaxation can be expressed as: ${ }^{14,15}$

$$
\frac{1}{T_{1}^{\mathrm{Q}}}=\frac{12 \pi^{2} \chi_{\mathrm{Q}}^{2}}{8}\left(1+\frac{\eta_{\mathrm{Q}}^{2}}{3}\right) \tau_{\mathrm{c}},
$$

where $\chi_{\mathrm{Q}}$ and $\eta_{\mathrm{Q}}$ are respectively the nuclear quadrupolar coupling constant and quadrupolar asymmetry parameter, and $\tau_{c}$ is the rotational correlation time. For ${ }^{14} \mathrm{~N}$ relaxation in an axially symmetrical MA cation, $\tau_{\mathrm{c}}$ refers to the spatial reorientation of the $\mathrm{C}-\mathrm{N}$ axis. Due to the fast axial rotation of MA cations, the effective $\eta_{\mathrm{Q}}$ is reduced to 0 in both tetragonal and cubic phases of $\mathrm{MAPbI}_{3}$, further simplifying eqn (1). To evaluate $\tau_{\mathrm{c}}$ we use $\chi_{\mathrm{Q}}\left({ }^{14} \mathrm{~N}\right)=0.68 \mathrm{MHz}$, obtained from our DFT MD simulations (discussed in detail below), resulting in correlation times of $1.0 \mathrm{ps}$ at $303 \mathrm{~K}$ (tetragonal phase) and $0.53 \mathrm{ps}$ at $333 \mathrm{~K}$ (cubic phase). These values indicate a rapid reorientation of the $\mathrm{C}-\mathrm{N}$ axis, and are in full agreement with previous reports. ${ }^{19,21,56}$ A much higher correlation time of $108 \mathrm{ps}$ has also been reported, ${ }^{28}$ however this value was obtained by a drastically different method that does not allow for a direct comparison.

The $T_{1}$ temperature dependences (in Arrhenius coordinates, Fig. $4 \mathrm{~b}$ ) are linear in both cubic and tetragonal phases, producing activation barriers of $0.1 \mathrm{eV}$ and $0.16 \mathrm{eV}$, respectively. These values cannot be directly compared with the one extracted in the ${ }^{15} \mathrm{~N}$ case (Fig. 3b), as the relaxation mechanisms involved are different. Nevertheless, they are fully in agreement with the ones extracted from other ${ }^{14} \mathrm{~N}$ NMR measurements. ${ }^{56}$ The observed decrease of the activation barrier across the phase transition implies a less hindered rotation of MA in the cubic phase, where the ${ }^{14} \mathrm{~N}$ signal
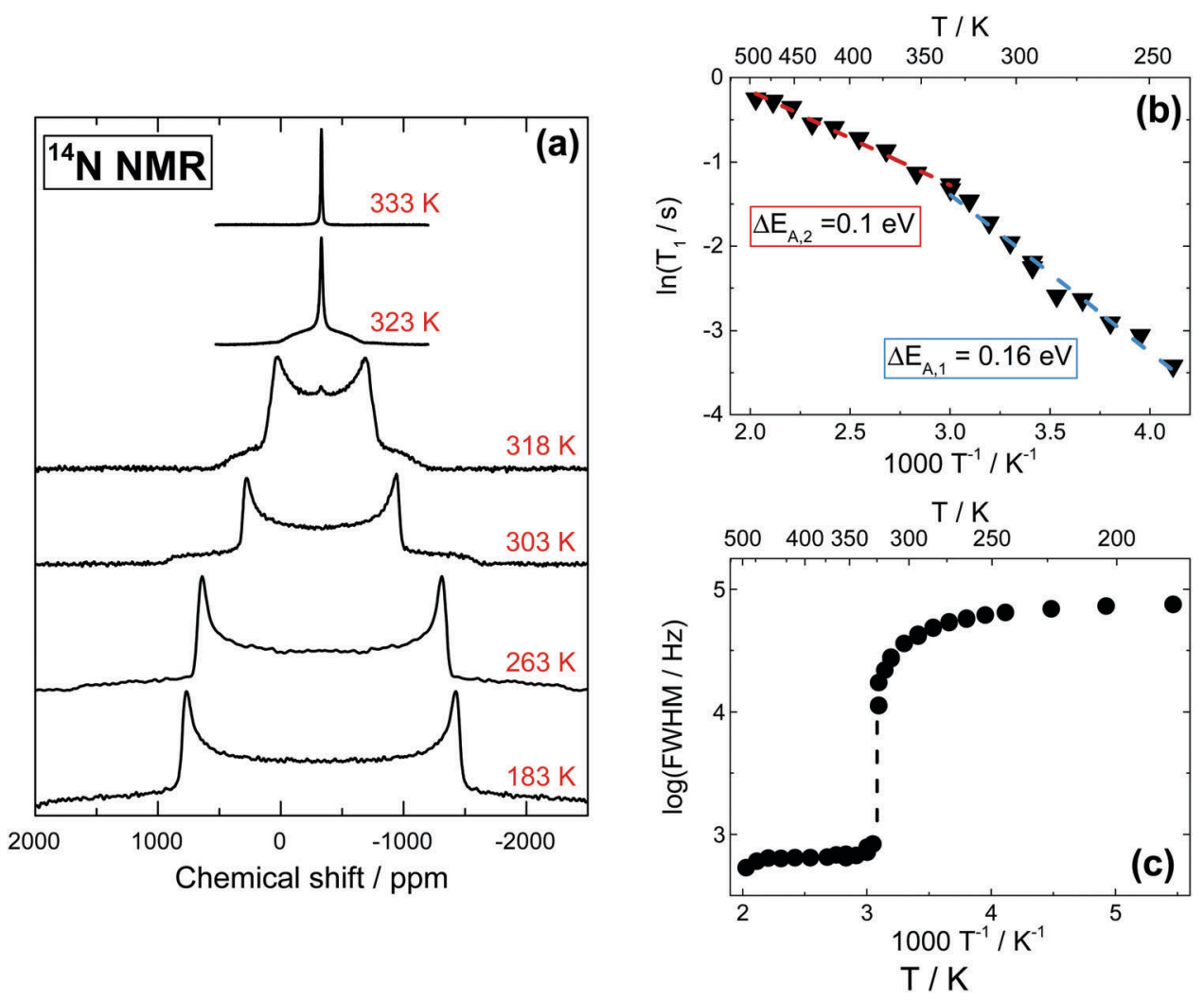

Fig. 4 (a) Variable temperature ${ }^{14} \mathrm{~N}$ NMR spectra in $\mathrm{MAPb}_{3}$, collected using a solid echo pulse sequence. No difference except in the overall intensity is observed between pure and partially labelled samples. (b) Arrhenius plot of ${ }^{14} \mathrm{~N} T_{1}$ relaxation times in MAPb/ 3 and (c) ${ }^{14} \mathrm{~N}$ FWHM as a function of temperature in $\mathrm{MAPbl}_{3}$. For the signals (tetragonal phase) demonstrating the quadrupolar splitting, the value of the splitting has been used in place of the FWHM. 
displays a Lorentzian line shape with FWHM of only $710 \mathrm{~Hz}$ at $333 \mathrm{~K}$, decreasing slowly as the temperature increases to $453 \mathrm{~K}$ (Fig. 4c). Such a small and steady change in the signal is consistent with a faster local motion of MA cations.

We can now focus on the analysis of the line shape of ${ }^{14} \mathrm{~N}$ spectra, in order to gain information on the modes of motion involving MA. In general, line shapes in ${ }^{14} \mathrm{~N}$ NMR depend on the interaction between the quadrupole moment of the nuclear spin and the EFG tensor surrounding the nucleus. In the specific case of a MA cation, this quadrupolar coupling is primarily of intramolecular origin, and is therefore strongly affected by the type and the rate of the MA molecular motions. Interestingly, the very large frequency spread of the experimental spectra (Fig. 4a) means that it is possible to probe molecular motion over a very broad frequency range. To help us identify the possible modes of motion involving MA, we performed ${ }^{14} \mathrm{~N}$ spectral simulations. In the general case of non-axial symmetry, the NMR frequencies $\left(\omega_{\mathrm{Q}}\right)$ in $a{ }^{14} \mathrm{~N}$ spectrum can be expressed as:

$$
\omega_{\mathrm{Q}}(\theta, \varphi)-\omega_{\mathrm{L}}=a \chi_{\mathrm{Q}} F(\eta, \theta, \varphi), \text { with } \chi_{\mathrm{Q}}=\frac{e Q}{h} V_{\mathrm{ZZ}}
$$

where $\omega_{\mathrm{L}}$ is the Larmor frequency, $a$ is a combination of constants, $F$ is a function defining the angular dependence of the EFG tensor, $\chi_{\mathrm{Q}}$ is the quadrupolar constant and $V_{\mathrm{zz}}$ the largest principal component of the EFG tensor. The asymmetry parameter $\eta$ describes the deviation from axial symmetry, while the polar angles $\theta$ and $\varphi$ define the tensor orientation with respect to the external magnetic field. The largest principal component of the EFG in MA is directed along the $\mathrm{C}-\mathrm{N}$ bond. A fast axial motion of a second rank tensor about an axis involving three or more equivalent sites will lead to an axially symmetric averaged tensor with $\eta=0$. Due to the intramolecular origin of quadrupole coupling in MA, one could expect the quadrupolar constant $\left(\chi_{\mathrm{Q}}\right)$ of the $\mathrm{N}$ atom in $\mathrm{MAPbI}_{3}$ to be similar to that in MA halogenates (values of $\chi_{\mathrm{Q}}=1.11 \mathrm{MHz}^{57}$ and $0.91 \mathrm{MHz}^{58}$ have been reported for $\mathrm{MACl}$ ). We test this hypothesis by performing periodic ab initio DFT MD simulation on a $3 \times 3 \times 3$ super-cell of $\mathrm{MAPbI}_{3}$. Interestingly, a rather different $\chi_{\mathrm{Q}}\left({ }^{14} \mathrm{~N}\right)$ of $0.68 \mathrm{MHz}$ with $\eta=0.52$ has been obtained by averaging over all nitrogen sites (Table S1, ESI $\dagger$ ), indicating a significant influence of the Pb-I framework on the EFG. These calculated EFG parameters are very close to those recently reported by Franssen et al., ${ }^{25}$ and have been used in our ${ }^{14} \mathrm{~N}$ spectral simulations.

As shown in Fig. 5, the ${ }^{14} \mathrm{~N}$ spectra are strongly and diversely influenced by the different internal motions considered, offering a way of discriminating among them. Looking at Fig. 5a, it is clear that a fast $\left(>10^{-6} \mathrm{~s}\right)$ continuous rotation around the $\mathrm{C}-\mathrm{N}$ axis (or equivalently fast $\geq 3$-sites symmetrical jumps) is necessary in order to produce the spectra experimentally observed in the tetragonal phase (Fig. 4a). Also, as shown in Fig. 5 b, by adding to a fast rotation around the $\mathrm{C}-\mathrm{N}$ bond a precessional motion with increasing angle $\theta$ (schematized in Fig. 5c), the quadrupolar splitting in the spectra reduces steadily until the angle reaches $54.7^{\circ}$, when it virtually disappears indicating nearly complete averaging of the quadrupolar interactions forming the line shape. This behavior is experimentally observed across the phase transition into the cubic phase (Fig. 4a and 5b), and corresponds to a pseudo-isotropic motion of MA cations within the inorganic framework. We recognize also that, in the cubic phase, identical spectra would be obtained with the presence of a fast enough isotropic motion, for example due to a translational diffusion of MA cations or to the presence of $180^{\circ}$ flips involving MA molecules. Both the former and the latter motion were clearly ruled out from previous electrochemical $^{13}$ and neutron scattering experiments ${ }^{48}$ respectively.

\section{${ }^{207} \mathrm{~Pb}$ NMR}

${ }^{207} \mathrm{~Pb}$ is a moderately sensitive spin-1/2 nucleus showing a remarkably broad range of chemical shifts (>8000 ppm) depending on its oxidation state and coordination environment, so much so that an unusually large difference $(\sim 1500 \mathrm{ppm})$ is found between the chemical shifts of $\mathrm{MAPbI}_{3}$ and $\mathrm{PbI}_{2}$. In order to rationalize this peculiar chemical shift behavior, we performed extensive DFT calculations of the ${ }^{207} \mathrm{~Pb}$ shielding in a series of lead compounds of known environment (results are summarized in Table S2, ESI $\dagger$ ). As shown in Fig. 6, the calculations correctly capture the general trend between the experimental chemical shifts and the different chemical environments, confirming the experimental observations. We recognize that the extracted slope in the shielding-shift trend (Fig. 6) has a value of almost 2 , while it would commonly not strongly deviate from 1. This semi-quantitative agreement, however, is likely due to the incomplete accounting for relativistic effects in $\mathrm{Pb}$ nuclei stemming from the use of pseudopotentials instead of the full electron wave functions and to the lack of spin-orbit effects in the valence wave functions.

The detection of ${ }^{207} \mathrm{~Pb}$ NMR in the solid state, particularly in iodine surroundings, presents a substantial challenge. As shown in Fig. 7a, the iodine environment around $\mathrm{Pb}$ nuclei causes a very short spin-spin relaxation time $T_{2}(\sim 20 \mu \mathrm{s})$ and a subsequent formidable broadening of the signals at temperatures above $250 \mathrm{~K}$ (Fig. 7b). The ${ }^{207} \mathrm{~Pb}$ linewidth remains nearly constant $(\sim 16.5 \mathrm{kHz})$ in the $433-253 \mathrm{~K}$ range, while below $253 \mathrm{~K}$ the line shape starts showing distinct asymmetry, consistently with the chemical shift anisotropy, and even significantly broadens at $173 \mathrm{~K}$. Lowering temperature also increases $T_{2}$ (Fig. 7b), reaching a peculiar 3-fold enhancement at $183 \mathrm{~K}$, even though the value falls back to $20 \mu \mathrm{s}$ at $173 \mathrm{~K}$ (near the orthorhombic phase transition), in agreement with previous reports. $^{25}$ This unusual behavior, which is also found in $T_{1}$ measurements (Fig. 7b), cannot be ascribed to standard relaxation mechanisms and common spectral density functions, but can be easily understood by taking into account strong spin-spin interactions between the spin-1/2 ${ }^{207} \mathrm{~Pb}$ nucleus and the quadrupolar ${ }^{127} \mathrm{I}$ nucleus. In this case, the ${ }^{207} \mathrm{~Pb} T_{2}$ is defined primarily by cross-relaxation to ${ }^{127} \mathrm{I}$, which presents very short relaxation times (Fig. 8c). Reducing the temperature slows down the cross-relaxation rate, yielding an increase in $T_{2}$ relaxation times. The transition to the orthorhombic phase 

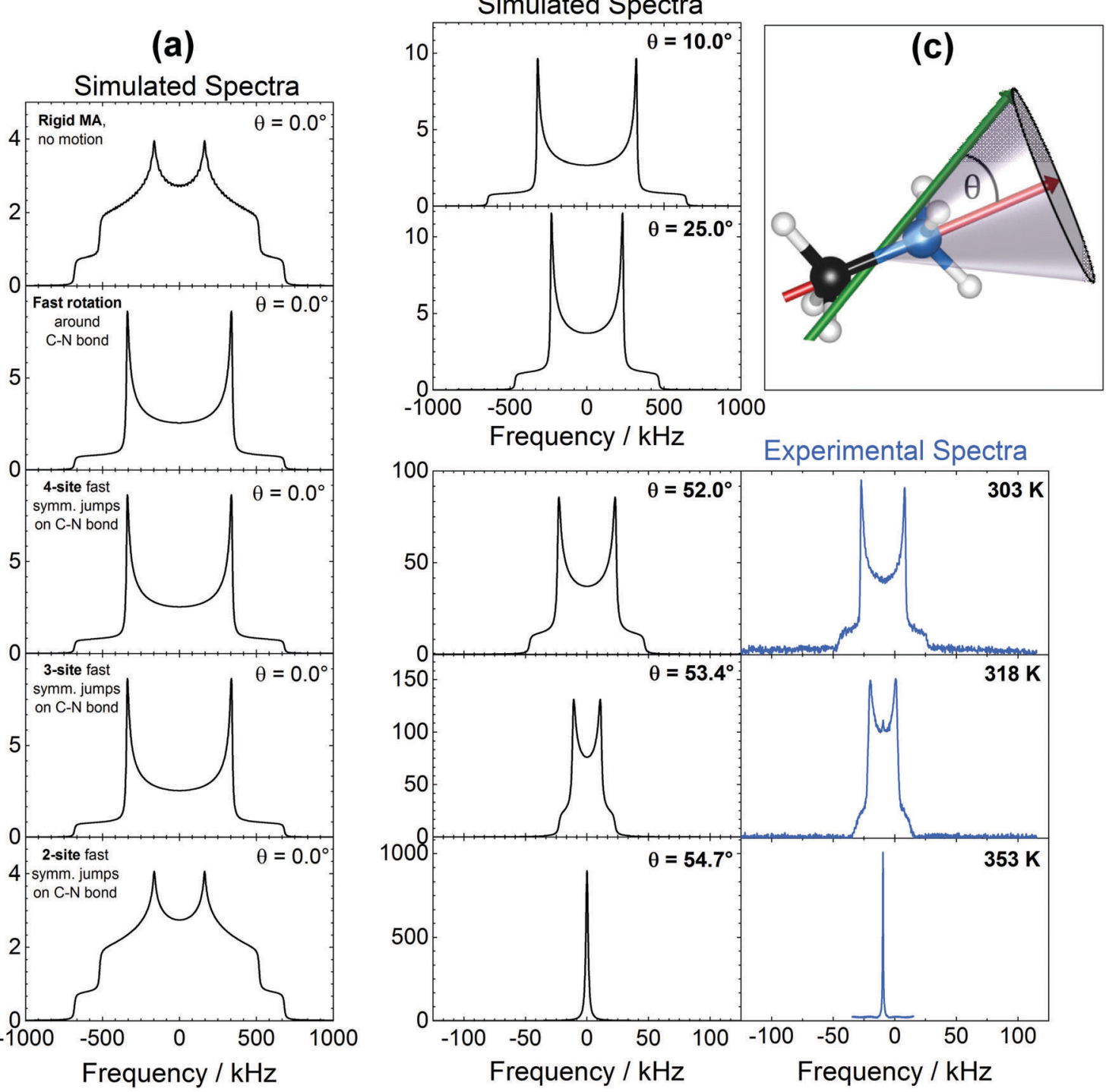

Fig. $5{ }^{14} \mathrm{~N}$ NMR spectral simulations assuming different MA modes of motion. (a) Simulated spectra in different dynamic conditions. (b) Simulated spectra obtained by modeling fast rotation around $\mathrm{C}-\mathrm{N}$ axis together with precession in conical fashion at different angles $\theta$. The data are compared with experimental spectra across the cubic phase transition. (c) Sketch of the modeled conical precessional motion.

appears to alter the dynamics of the spin-exchange, resulting again in a shorter $T_{2}$.

Focusing now on spin-lattice relaxation, the magnitude of ${ }^{207} \mathrm{~Pb} T_{1}$ in $\mathrm{MAPbI}_{3}$ is similar to that previously reported for $\mathrm{PbI}_{2} \cdot{ }^{59}$ As shown in Fig. $7 \mathrm{~b}, T_{1}$ is practically independent of the magnetic field and depends only marginally on the temperature. Also, $T_{1}$ temperature dependences in ${ }^{127} \mathrm{I}$ and ${ }^{207} \mathrm{~Pb}$ appear rather similar (Fig. 8c and 7b), clearly demonstrating the large influence of cross-relaxation to ${ }^{127} \mathrm{I}$ on the ${ }^{207} \mathrm{~Pb}$ spin-lattice relaxation process. An additional proof of such coupling is that $T_{1}$ is strongly affected by MAS, decreasing by more than 1 order of magnitude under spinning conditions (Fig. 7b, details in the caption). This effect was recently reported and discussed in detail for lead and mercury halides, ${ }^{60}$ where in the specific case of $\mathrm{PbI}_{2}$ MAS conditions were required to induce the $\mathrm{Pb}-\mathrm{I}$ coupling; unsurprisingly, thanks to the much stronger quadrupolar interactions, in $\mathrm{MAPbI}_{3}$ the coupling is present already in stationary conditions (Fig. 7a).

As a last point, we discuss the temperature dependence of the ${ }^{207} \mathrm{~Pb}$ isotropic chemical shift $\left(\delta_{\text {iso }}\right)$. As shown in Fig. 7c, $\delta_{\text {iso }}$ exhibits a distinct temperature dependence, as commonly observed in lead compounds ${ }^{61-64}$ and also in $\mathrm{MAPbCl}_{3}{ }^{29}$ even though our experimental data show a small but detectable deviation from the normally reported linear dependences. For $\mathrm{MAPbI}_{3}$, this temperature dependence can be fully attributed to changes in the lattice parameters, ${ }^{25}$ as it is usually the case in $\mathrm{Pb}$ compounds. ${ }^{61-64}$ We note that this temperature dependence shows no clear sign of the cubic phase transition. 


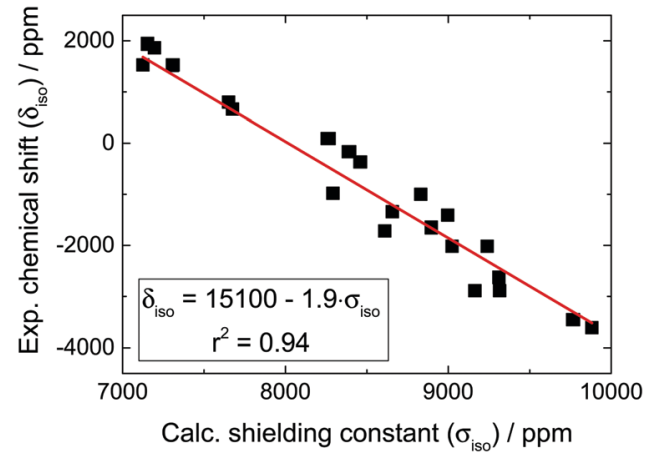

Fig. 6 Correlation between calculated isotropic shielding and experimental ${ }^{207} \mathrm{~Pb}$ isotropic chemical shifts in various diamagnetic compounds of lead. All experimental data are taken from the literature, with their corresponding ICSD numbers given in Table S2 (ESI†). The chemical shift of lead is referenced to lead tetramethyl $\left(\delta_{\text {iso }}=0 \mathrm{ppm}\right)$.

\section{${ }^{127}$ I NQR}

${ }^{127} \mathrm{I}$ is a quadrupolar spin-5/2 nucleus with $100 \%$ natural abundance and reasonably high Larmor frequency, and thus could be considered a high receptivity nucleus. However, due to its very high quadrupole moment $\left(-69.6 \mathrm{fm}^{2}\right),{ }^{65}{ }^{127}$ I NMR must be restricted to systems with a relatively high symmetry ${ }^{66}$ (for $\mathrm{MAPbI}_{3}$, preliminary ${ }^{127} \mathrm{I} \mathrm{NMR}$ spectra have been reported in ref. 13). In $\mathrm{MAPbI}_{3}$, however, a significant EFG at the iodine sites $\left(\chi_{\mathrm{Q}}>550 \mathrm{MHz}\right)$ provides a good sensitivity in NQR spectroscopy, offering an alternative method to probe the I-environment in this material. As shown in Fig. 8a, two pairs of transitions in ${ }^{127} \mathrm{I}$ NQR are detected for the two distinct iodine sites present in the tetragonal phase, while in the cubic phase only 2 signals are observed, corresponding to conversion into a single iodine site. The resonance frequencies of the signals, along with the quadrupolar constant $\chi_{\mathrm{Q}}$, show appreciable temperature dependence (Fig. 8b and Fig. S9, ESI $\dagger$ ), a behavior that is commonly attributed to a planar-torsional oscillation of a resonant nucleus (I) about another atom to which it is bonded $(\mathrm{Pb})$.

The temperature dependence of the ${ }^{127} \mathrm{I}$ quadrupole resonance frequency in $\mathrm{MAPbI}_{3}$ can be estimated based on the Bayer theory ${ }^{67}$ of torsional oscillations of atoms in the lattice. ${ }^{68}$ In this model the nuclei are agitated by the torsional motion at a rate that is very fast compared to their NQR frequencies, and they are therefore affected by an averaged temperaturedependent EFG that is different from the stationary situation (details in Section 8 and Fig. S9, ESI $\dagger$ ). Thanks to this approach, $^{68}$ it is possible to fit the experimental data and extract a torsional frequency $\nu_{\mathrm{t}} \approx 1.15 \mathrm{THz}$, corresponding to $38 \mathrm{~cm}^{-1}$. For a simple comparison, the reported Raman frequencies for $\mathrm{Pb}-\mathrm{I}$ contributions in $\mathrm{MAPbI}_{3}$ were calculated to be between $20-50 \mathrm{~cm}^{-1}$, with a perceptible coupling to MA-modes. ${ }^{69,70}$ Another work, instead, experimentally observed
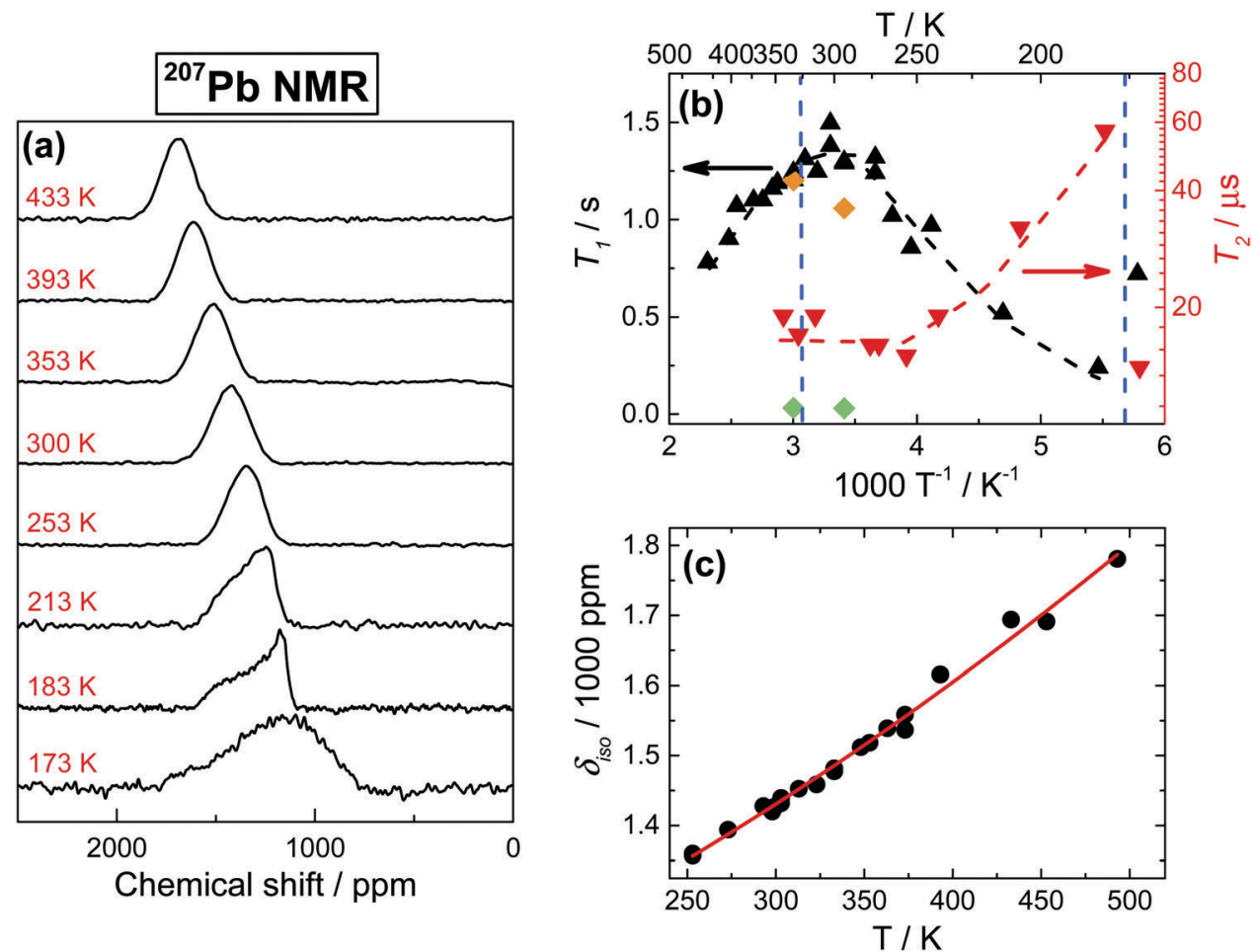

Fig. 7 (a) ${ }^{207} \mathrm{~Pb}$ NMR spectra of $\mathrm{MAPb}_{3}$ as a function of temperature. (b) Temperature dependence of ${ }^{207} \mathrm{~Pb}$ spin-lattice and spin-spin relaxation times $T_{1}$ and $T_{2}$. Dashed lines are only to guide the eye. Vertical lines indicate the phase transitions. Orange ( $\left.\$\right)$ and green ( $\left.\$\right)$ points are $T_{1}$ relaxation times collected at $21.1 \mathrm{~T}$ in stationary and $8 \mathrm{kHz}$ MAS conditions respectively. Note that the higher field has no influence on $T_{1}$ for stationary samples, while spinning greatly reduces it down to $20-30 \mathrm{~ms}$. (c) Isotropic chemical shift of ${ }^{207} \mathrm{~Pb}$ signal as a function of temperature, fitted with a quadratic equation $\delta_{\text {iso }}=1.04+0.96 T+0.001 T^{2}$ 

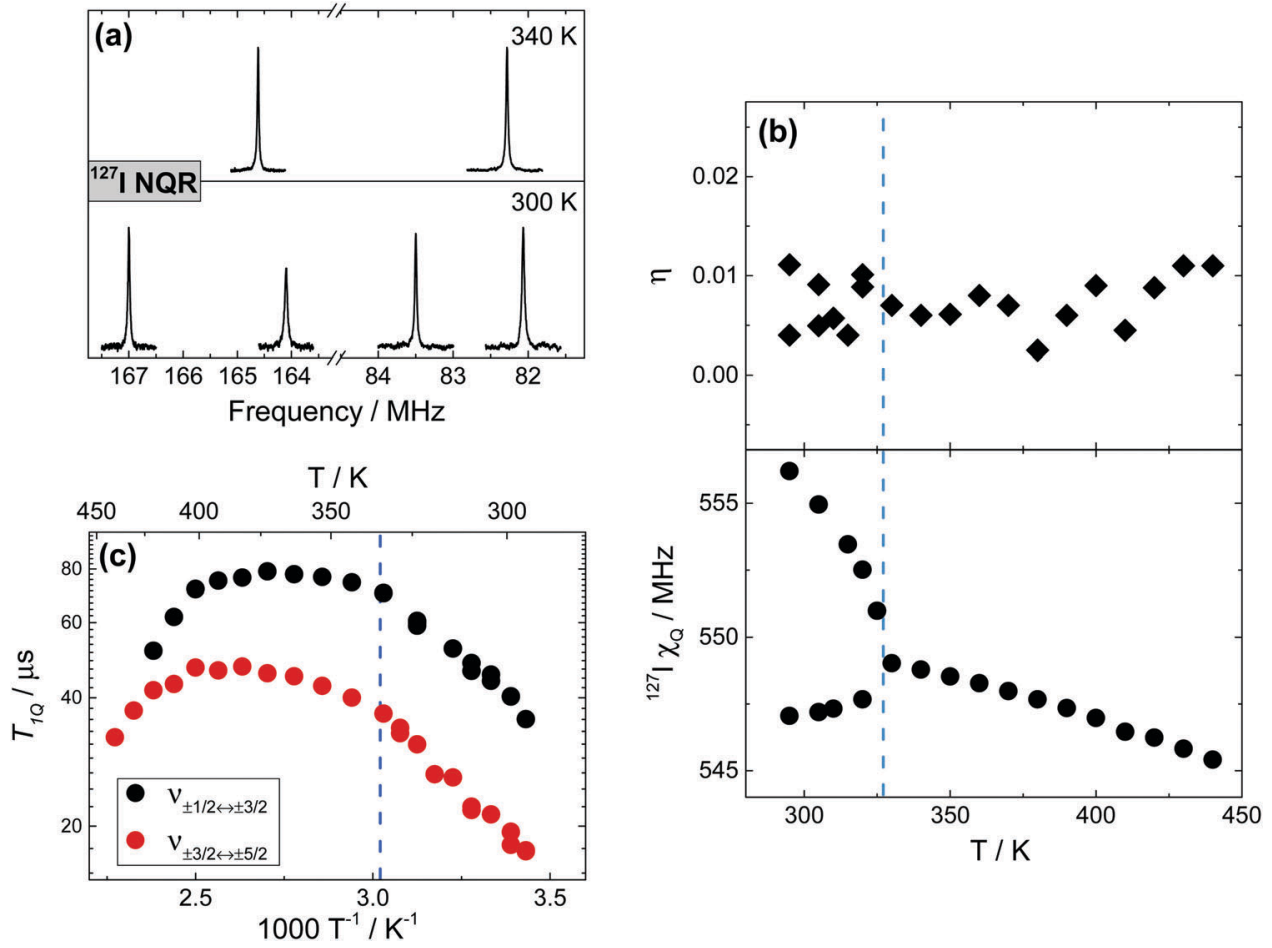

Fig. 8 (a) ${ }^{127}$ I NQR signals in $\mathrm{MAPb}_{3}$ at $300 \mathrm{~K}$ (tetragonal phase) and at $340 \mathrm{~K}$ (cubic phase). (b) Temperature dependence of the ${ }^{127}$ I quadrupolar coupling constant $\chi_{\mathrm{Q}}$ and of the asymmetry parameter $\eta$. Phase transition is visible at $327 \mathrm{~K}$ (blue line). (c) Quadrupolar spin-lattice relaxation time $T_{1 \mathrm{Q}}$ as a function of temperature.

$\mathrm{Pb}-\mathrm{I}$ vibrations at higher frequencies $\left(75-125 \mathrm{~cm}^{-1}\right)$, also here with contributions coming from MA-modes. ${ }^{71}$ In addition, as shown in Fig. 8c, we record the quadrupolar spin-lattice relaxation time $\left(T_{10}\right)$ for ${ }^{127} \mathrm{I}$ as a function of temperature. Again according to the Bayer theory, ${ }^{67}$ this temperature dependence can be used to calculate an accurate estimate of the correlation time $\tau_{\mathrm{a}}$ of the torsional vibrations, albeit a closed solution for a spin $5 / 2$ nucleus does not exist. ${ }^{72}$ Under certain assumptions, a partial solution can still be found for our system, but only in a very narrow temperature range $(290-340 \mathrm{~K})$, making the obtained $\tau_{\mathrm{a}}$ values of $2 \times 10^{-10} \mathrm{~s}(290 \mathrm{~K})$ and $4 \times 10^{-10} \mathrm{~s}$ $(340 \mathrm{~K})$ only indicative. We refer the reader to the ESI, $\dagger$ (Section 8) for the complete treatment and related assumptions.

\section{Conclusions}

In conclusions, we have shown that much information on halide perovskites can be collected by means of NMR spectroscopy. Specifically, we studied the short-range ion dynamics in $\mathrm{MAPbI}_{3}$ in a broad temperature range using ${ }^{1} \mathrm{H},{ }^{13} \mathrm{C},{ }^{14,15} \mathrm{~N},{ }^{207} \mathrm{~Pb}$ multinuclear solid-state NMR and ${ }^{127} \mathrm{I}$ NQR. We found that the motion of the MA cation is ascribable to that of a symmetrical rotor, with similar interactions of $\mathrm{CH}_{3}$ and $\mathrm{NH}_{3}{ }^{+}$groups with the inorganic lattice. Specifically, the predominant mode of motion for the MA cation is identified as a bi-axial rotation, as supported by ${ }^{14} \mathrm{~N}$ NMR and related spectral simulations. This rotation becomes nearly isotropic above the cubic phase transition, and sufficiently fast to dominate the relaxation mechanism through spin-rotational interactions. Regarding the inorganic lattice, ${ }^{207} \mathrm{~Pb}$ NMR shows strong cross-relaxation to quadrupolar ${ }^{127} \mathrm{I}$, which ultimately fully dominates the ${ }^{207} \mathrm{~Pb}$ spin-lattice relaxation times $T_{1}$ and severely influences the linewidth $\left(T_{2}\right)$. The temperature behavior of ${ }^{127}$ I NQR spectra is indicative of a torsional oscillation of I about $\mathrm{Pb}$ atoms, where the frequency of oscillations can be estimated.

\section{Conflicts of interest}

There are no conflicts to declare.

\section{Acknowledgements}

The authors thank V. Terskikh (University of Ottawa, Canada) for help with the UHF NMR experiments. Access to the $900 \mathrm{MHz}$ NMR spectrometer was provided by the National Ultrahigh Field NMR Facility for Solids managed by University of Ottawa, Ottawa, Canada (http://www.nmr900.ca). Dr Helga Hoier is thanked for performing the XRD measurements. Open Access funding provided by the Max Planck Society.

\section{References}

1 A. Kojima, K. Teshima, Y. Shirai and T. Miyasaka, Organometal Halide Perovskites as Visible-Light Sensitizers for Photovoltaic Cells, J. Am. Chem. Soc., 2009, 131(17), 6050-6051, DOI: 10.1021/ja809598r. 
2 H.-S. Kim, C.-R. Lee, J.-H. Im, K.-B. Lee, T. Moehl and A. Marchioro, et al., Lead Iodide Perovskite Sensitized All-Solid-State Submicron Thin Film Mesoscopic Solar Cell with Efficiency Exceeding 9\%, Sci. Rep., 2012, 2(1), 591.

3 M. M. Lee, J. Teuscher, T. Miyasaka, T. N. Murakami and H. J. Snaith, Efficient Hybrid Solar Cells Based on MesoSuperstructured Organometal Halide Perovskites, Science, 2012, 338(6107), 643-647.

4 D. Weber, $\mathrm{CH}_{3} \mathrm{NH}_{3} \mathrm{PbX}_{3}$, ein $\mathrm{Pb}(\mathrm{II})$-System mit kubischer Perowskitstruktur/ $\mathrm{CH}_{3} \mathrm{NH}_{3} \mathrm{PbX}_{3}$, a $\mathrm{Pb}$ (II)-System with Cubic Perovskite Structure, Zeitschrift für Naturforsch B., 1978, 33(12), 1443-1445.

5 C. C. Stoumpos, C. D. Malliakas and M. G. Kanatzidis, Semiconducting Tin and Lead Iodide Perovskites with Organic Cations: Phase Transitions, High Mobilities, and Near-Infrared Photoluminescent Properties, Inorg. Chem., 2013, 52(15), 9019-9038, DOI: 10.1021/ic401215x.

6 J. Ma and L.-W. Wang, The Nature of Electron Mobility in Hybrid Perovskite $\mathrm{CH}_{3} \mathrm{NH}_{3} \mathrm{PbI}_{3}$, Nano Lett., 2017, 17(6), 3646-3654, DOI: 10.1021/acs.nanolett.7b00832.

7 C. Motta, F. El-Mellouhi, S. Kais, N. Tabet, F. Alharbi and S. Sanvito, Revealing the role of organic cations in hybrid halide perovskite $\mathrm{CH}_{3} \mathrm{NH}_{3} \mathrm{PbI}_{3}$, Nat. Commun., 2015, 6(1), 7026.

8 J. Gong, M. Yang, X. Ma, R. D. Schaller, G. Liu and L. Kong, et al., Electron-Rotor Interaction in Organic-Inorganic Lead Iodide Perovskites Discovered by Isotope Effects, J. Phys. Chem. Lett., 2016, 7(15), 2879-2887.

9 J. H. Lee, J.-H. Lee, E.-H. Kong and H. M. Jang, The nature of hydrogen-bonding interaction in the prototypic hybrid halide perovskite, tetragonal $\mathrm{CH}_{3} \mathrm{NH}_{3} \mathrm{PbI}_{3}$, Sci. Rep., 2016, 6(1), 21687.

10 E. Mosconi, A. Amat, M. K. Nazeeruddin, M. Grätzel and F. De Angelis, First-Principles Modeling of Mixed Halide Organometal Perovskites for Photovoltaic Applications, J. Phys. Chem. C, 2013, 117(27), 13902-13913.

11 A. Amat, E. Mosconi, E. Ronca, C. Quarti, P. Umari and M. K. Nazeeruddin, et al., Cation-Induced Band-Gap Tuning in Organohalide Perovskites: Interplay of Spin-Orbit Coupling and Octahedra Tilting, Nano Lett., 2014, 14(6), 3608-3616, DOI: 10.1021/nl5012992.

12 C. Quarti, E. Mosconi and F. De Angelis, Interplay of Orientational Order and Electronic Structure in Methylammonium Lead Iodide: Implications for Solar Cell Operation, Chem. Mater., 2014, 26(22), 6557-6569, DOI: 10.1021/ cm5032046.

13 A. Senocrate, I. Moudrakovski, G. Y. Kim, T.-Y. Yang, G. Gregori and M. Grätzel, et al., The Nature of Ion Conduction in Methylammonium Lead Iodide: A Multimethod Approach, Angew. Chem., Int. Ed., 2017, 56(27), 7755-7759.

14 C. P. Slichter, Principles of Magnetic Resonance, SpringerVerlag Berlin Heidelberg, 1990, p. 658.

15 A. Abragam, The principles of nuclear magnetism, Oxford University Press, 1961.

16 K. J. D. MacKenzie and M. E. Smith, in Multinuclear SolidState NMR of Inorganic Materials, ed. MacKenzie K. J. D. and
Smith M. E., Pergamon Materials Series, Pergamon, 2002, vol. 6.

17 M. J. Duer, Introduction to Solid-State NMR Spectroscopy, Blackweell Publishing, Oxford, 2004.

18 V. I. Bakhmutov, Solid State NMR in Materials Science, CRC Press, 2011, p. 280.

19 R. E. Wasylishen, O. Knop and J. B. Macdonald, Cation rotation in methylammonium lead halides, Solid State Commun., 1985, 56(7), 581-582.

20 Y. Furukawa and D. Nakamura, Cation Dynamics in the Crystalline Phases of $\left(\mathrm{CH}_{3} \mathrm{NH}_{3}\right) \mathrm{PbX}_{3}(\mathrm{X}: \mathrm{Cl}, \mathrm{Br})$ as Studied by Proton Magnetic Resonance Techniques, Z. Naturforsch., 1989, 44a(1989), 1122-1126.

21 O. Knop, R. E. Wasylishen, M. A. White, T. S. Cameron and M. J. M. Van Oort, Alkylammonium lead halides. Part 2. $\mathrm{CH}_{3} \mathrm{NH}_{3} \mathrm{PbX}_{3}(\mathrm{X}=\mathrm{Cl}, \mathrm{Br}, \mathrm{I})$ perovskites: cuboctahedral halide cages with isotropic cation reorientation, Can. J. Chem., 1990, 68(3), 412-422, DOI: 10.1139/v90-063.

22 Q. Xu, T. Eguchi, H. Nakayama, N. Nakamura and M. Kishita, Molecular Motions and Phase Transitions in Solid $\mathrm{CH}_{3} \mathrm{NH}_{3} \mathrm{PbX}_{3}(\mathrm{X}=\mathrm{Cl}, \mathrm{Br}, \mathrm{I})$ as Studied by NMR and NQR, Zeitschrift für Naturforsch A., 1991, 46(3), 240-246.

23 A. Poglitsch and D. Weber, Dynamic disorder in methylammoniumtrihalogenoplumbates(II) observed by millimeter wave spectroscopy, J. Chem. Phys., 1987, 87, 11.

24 A. M. Askar, G. M. Bernard, B. Wiltshire, K. Shankar and V. K. Michaelis, Multinuclear Magnetic Resonance Tracking of Hydro, Thermal, and Hydrothermal Decomposition of $\mathrm{CH}_{3} \mathrm{NH}_{3} \mathrm{PbI}_{3}$, J. Phys. Chem. C, 2017, 121(2), 1013-1024.

25 W. M. J. Franssen, S. G. D. van Es, R. Dervişoğlu, G. A. de Wijs and A. P. M. Kentgens, Symmetry, Dynamics, and Defects in Methylammonium Lead Halide Perovskites, J. Phys. Chem. Lett., 2017, 8(1), 61-66, DOI: 10.1021/acs.jpclett.6b02542.

26 T. Baikie, N. S. Barrow, Y. Fang, P. J. Keenan, P. R. Slater and R. O. Piltz, et al., A combined single crystal neutron/X-ray diffraction and solid-state nuclear magnetic resonance study of the hybrid perovskites $\mathrm{CH}_{3} \mathrm{NH}_{3} \mathrm{PbX}_{3}(\mathrm{X}=\mathrm{I}, \mathrm{Br}$ and $\mathrm{Cl}$ ), J. Mater. Chem. A, 2015, 3(17), 9298-9307, DOI: 10.1039/C5TA01125F.

27 C. Roiland, G. Trippé-Allard, K. Jemli, B. Alonso, J.-C. Ameline and R. Gautier, et al., Multinuclear NMR as a tool for studying local order and dynamics in $\mathrm{CH}_{3} \mathrm{NH}_{3} \mathrm{PbX}_{3}$ (X $=\mathrm{Cl}, \mathrm{Br}, \mathrm{I})$ hybrid perovskites, Phys. Chem. Chem. Phys., 2016, 18(39), 27133-27142, DOI: 10.1039/C6CP02947G.

28 D. J. Kubicki, D. Prochowicz, A. Hofstetter, P. Péchy, S. M. Zakeeruddin and M. Grätzel, et al., Cation Dynamics in Mixed-Cation (MA) $x(\mathrm{FA}) 1-x \mathrm{PbI}_{3}$ Hybrid Perovskites from Solid-State NMR, J. Am. Chem. Soc., 2017, 139(29), 10055-10061, DOI: $10.1021 /$ jacs.7b04930.

29 G. M. Bernard, A. Goyal, M. Miskolzie, R. McKay, Q. Wu and R. E. Wasylishen, et al., Methylammonium lead chloride: A sensitive sample for an accurate NMR thermometer, J. Magn. Reson., 2017, 283, 14-21.

30 J.-H. Im, C.-R. Lee, J.-W. Lee, S.-W. Park and N.-G. Park, 6.5\% efficient perovskite quantum-dot-sensitized solar cell, Nanoscale, 2011, 3(10), 4088-4093, DOI: 10.1039/C1NR10867K. 
31 M. I. Saidaminov, A. L. Abdelhady, B. Murali, E. Alarousu, V. M. Burlakov and W. Peng, et al., High-quality bulk hybrid perovskite single crystals within minutes by inverse temperature crystallization, Nat. Commun., 2015, 6, 7586.

32 E. Fukushima and S. B. W. Roeder, Experimental Pulse NMR: A nuts and bolts approach, Addison-Wesley, 1981, p. 539.

33 A. Bielecki and D. P. Burum, Temperature Dependence of ${ }^{207} \mathrm{~Pb}$ MAS Spectra of Solid Lead Nitrate. An Accurate, Sensitive Thermometer for Variable-Temperature MAS, J. Magn. Reson., Ser. A, 1995, 116(2), 215-220.

34 R. K. Harris, E. D. Becker, S. M. Cabral De Menezes, R. Goodfellow and P. Granger, NMR nomenclature. Nuclear spin properties and conventions for chemical shifts (IUPAC recommendations 2001), Pure Appl. Chem., 2001, 73(11), 1795-1818.

35 M. D. Segall, P. J. D. Lindan, M. I. J. Probert, C. J. Pickard, P. J. Hasnip and S. J. Clark, et al., First-principles simulation: ideas, illustrations and the CASTEP code, J. Phys.: Condens. Matter, 2002, 14(11), 2717-2744.

36 J. R. Yates, C. J. Pickard and F. Mauri, Calculation of NMR chemical shifts for extended systems using ultrasoft pseudopotentials, Phys. Rev. B: Condens. Matter Mater. Phys., 2007, 76(2), 24401, DOI: 10.1103/PhysRevB.76.024401.

37 J. P. Perdew, K. Burke and Y. Wang, Generalized gradient approximation for the exchange-correlation hole of a manyelectron system, Phys. Rev. B: Condens. Matter Mater. Phys., 1996, 54(23), 16533-16539.

38 H. J. Monkhorst and J. D. Pack, Special points for Brillouinzone integrations, Phys. Rev. B: Condens. Matter Mater. Phys, 1976, 13(12), 5188-5192, DOI: 10.1103/PhysRevB.13.5188.

39 E. van Lenthe, E. J. Baerends and J. G. Snijders, Relativistic total energy using regular approximations, J. Chem. Phys., 1994, 101(11), 9783-9792, DOI: 10.1063/1.467943.

40 E. van Lenthe, J. G. Snijders and E. J. Baerends, The zeroorder regular approximation for relativistic effects: the effect of spin-orbit coupling in closed shell molecules, J. Chem. Phys., 1996, 105(15), 6505-6516, DOI: 10.1063/1.472460.

41 C. Bonhomme, C. Gervais, F. Babonneau, C. Coelho, F. Pourpoint and T. Azaïs, et al., First-Principles Calculation of NMR Parameters Using the Gauge Including Projector Augmented Wave Method: A Chemist's Point of View, Chem. Rev., 2012, 112(11), 5733-5779, DOI: 10.1021/cr300108a.

42 D. Massiot, F. Fayon, M. Capron, I. King, S. Le Calvé and B. Alonso, et al., Modelling one- and two-dimensional solid-state NMR spectra, Magn. Reson. Chem., 2002, 40(1), 70-76.

43 V. Macho, L. Brombacher and H. W. Spiess, The NMRWEBLAB: an internet approach to NMR lineshape analysis, Appl. Magn. Reson., 2001, 20(3), 405-432, DOI: 10.1007/ BF03162288.

44 R. L. Vold and G. L. Hoatson, Effects of jump dynamics on solid state nuclear magnetic resonance line shapes and spin relaxation times, J. Magn. Reson., 2009, 198(1), 57-72.

45 A. M. Gil and E. Alberti, The effect of Magic Angle Spinning on proton spin-lattice relaxation times in some organic solids, Solid State Nucl. Magn. Reson., 1998, 11(3-4), 203-209.
46 S. Hayashi, Effects of magic-angle spinning on spin-lattice relaxations in talc, Solid State Nucl. Magn. Reson., 1994, 3(6), 323-330.

47 J. G. Powles and H. S. Gutowsky, Proton Magnetic Resonance of the $\mathrm{CH}_{3}$ Group. II. Solid Solutions of $t$-Butyl Chloride in Carbon Tetrachloride, J. Chem. Phys., 1953, 21(10), 1704-1709, DOI: 10.1063/1.1698646.

48 A. M. Leguy, J. M. Frost, A. P. McMahon, V. G. Sakai, W. Kochelmann and C. Law, et al., The dynamics of methylammonium ions in hybrid organic-inorganic perovskite solar cells, Nat. Commun., 2015, 6, 7124.

49 E. R. Andrew and R. Bersohn, Nuclear Magnetic Resonance Line Shape for a Triangular Configuration of Nuclei, J. Chem. Phys., 1950, 18(2), 159-561, DOI: 10.1063/1.1747579.

50 H. S. Gutowsky and G. E. Pake, Structural Investigations by Means of Nuclear Magnetism. II. Hindered Rotation in Solids, J. Chem. Phys., 1950, 18(2), 162-170, DOI: 10.1063/ 1.1747580 .

51 N. Bloembergen, E. M. Purcell and R. V. Pound, Relaxation effects in nuclear magnetic resonance absorption, Phys. Rev., 1948, 73(7), 679-712, DOI: 10.1103/PhysRev.73.679.

52 A. M. Panich, N. A. Sergeev and M. Olszewski, Effect of magic angle spinning on ${ }^{13} \mathrm{C}$ spin-lattice and spin-spin relaxation in nanodiamonds, J. Phys.: Condens. Matter, 2015, 27(36), 365302.

53 J. L. Sudmeier, S. E. Anderson and J. S. Frye, Calculation of Nuclear Spin Relaxation Times, Concepts Magn. Reson., 1990, 2(4), 197-212, DOI: 10.1002/cmr.1820020403.

54 R. Ikeda and C. A. McDowell, Spin-rotational relaxation for protons in solid, $\mathrm{NH}_{4} \mathrm{ClO}_{4}$, Chem. Phys. Lett., 1972, 14(4), 389-392.

55 V. I. Bakhmutov, Practical NMR Relaxation for Chemists, John Wiley \& Sons Ltd, Chichester, UK, 2004, DOI: 10.1002/ 0470094486.

56 G. M. Bernard, R. E. Wasylishen, C. I. Ratcliffe, V. Terskikh, Q. Wu and J. M. Buriak, et al., Methylammonium Cation Dynamics in Methylammonium Lead Halide Perovskites: A Solid-State NMR Perspective, J. Phys. Chem. A, 2018, 122(6), 1560-1573, DOI: 10.1021/acs.jpca.7b11558.

57 P. Polatin, T. Barbara and B. P. Dailey, The determination of the ${ }^{14} \mathrm{~N}$ nuclear quadrupole coupling constant for the methylammonium ion in a liquid-crystal solution, J. Magn. Reson., 1982, 47(1), 148-150.

58 D. T. Edmonds, M. J. Hunt and A. L. Mackay, Pure quadrupole resonance of ${ }^{14} \mathrm{~N}$ in a tetrahedral environment, J. Magn. Reson., 1973, 9(1), 66-74.

59 R. E. Taylor, P. A. Beckmann, S. Bai and C. Dybowski, ${ }^{127}$ I and ${ }^{207} \mathrm{~Pb}$ Solid-State NMR Spectroscopy and Nuclear Spin Relaxation in $\mathrm{PbI}_{2}$ : A Preliminary Study, J. Phys. Chem. C, 2014, 118(17), 9143-9153, DOI: 10.1021/jp5023423.

60 A. A. Shmyreva, M. Safdari, I. Furó and S. V. Dvinskikh, NMR longitudinal relaxation enhancement in metal halides by heteronuclear polarization exchange during magic-angle spinning, J. Chem. Phys., 2016, $144(22), 224201$.

61 T. Mildner, H. Ernst and D. Freude, ${ }^{207} \mathrm{~Pb}$ NMR detection of spinning-induced temperature gradients in MAS rotors, Solid State Nucl. Magn. Reson., 1995, 5(3), 269-271. 
62 P. A. Beckmann and C. Dybowski, A Thermometer for Nonspinning Solid-State NMR Spectroscopy, J. Magn. Reson., 2000, 146(2), 379-380.

63 T. Takahashi, H. Kawashima, H. Sugisawa and T. Baba, ${ }^{207} \mathrm{~Pb}$ chemical shift thermometer at high temperature for magic angle spinning experiments, Solid State Nucl. Magn. Reson., 1999, 15(2), 119-123.

64 L. C. M. van Gorkom, J. M. Hook, M. B. Logan, J. V. Hanna and R. E. Wasylishen, Solid-state lead-207 NMR of lead(II) nitrate: localized heating effects at high magic angle spinning speeds, Magn. Reson. Chem., 1995, 33(10), 791-795, DOI: $10.1002 / \mathrm{mrc} .1260331005$.

65 P. Pyykko, Year-2008 nuclear quadrupole moments, Mol. Phys., 2008, 106(16-18), 1965-1974.

66 D. L. Bryce, C. M. Widdifield, R. P. Chapman and R. J. Attrell, Chlorine, Bromine, and Iodine Solid-State NMR, eMagRes, John Wiley \& Sons, Ltd, 2007, DOI: 10.1002/ 9780470034590.emrstm1214.

67 H. Bayer, Zur Theorie der Spin-Gitterrelaxation in Molekülkristallen, Zeitschrift für Phys., 1951, 130(2), 227-238, DOI: 10.1007/BF01337696.
68 J. Ramakrishna, Temperature Dependence of the Iodine Pure Quadrupole Resonance Frequency in Methyl Iodide, Proc. Phys. Soc., 1962, 79(5), 1069. Available from: http:// stacks.iop.org/0370-1328/79/i=5/a=320.

69 F. Brivio, J. M. Frost, J. M. Skelton, A. J. Jackson, O. J. Weber and M. T. Weller, et al., Lattice dynamics and vibrational spectra of the orthorhombic, tetragonal, and cubic phases of methylammonium lead iodide, Phys. Rev. B: Condens. Matter Mater. Phys., 2015, 92(14), 144308, DOI: 10.1103/ PhysRevB.92.144308.

70 T. Hata, G. Giorgi and K. Yamashita, The Effects of the Organic-Inorganic Interactions on the Thermal Transport Properties of $\mathrm{CH}_{3} \mathrm{NH}_{3} \mathrm{PbI}_{3}$, Nano Lett., 2016, 16(4), 2749-2753.

71 P. Pistor, A. Ruiz, A. Cabot and V. Izquierdo-Roca, Advanced Raman Spectroscopy of Methylammonium Lead Iodide: Development of a Non-destructive Characterisation Methodology, Sci. Rep., 2016, 6, 35973.

72 A. C. Daniel and W. G. Moulton, Temperature Dependence of Pure Nuclear Quadrupole Spin-Lattice Relaxation in $\mathrm{SnI}_{4}$, J. Chem. Phys., 1964, 41(6), 1833-1846. 